Review

\title{
Acupuncture and blood borne viral infections: a brief summary
}

\author{
Viroj Wiwanitkit* \\ Visiting University Professor, Hainan Medical University, China; Wiwanitkit House, Bangkhae, Bangkok, Thailand 10160
}

\begin{abstract}
Blood borne infectious diseases are usually a public concern. The transmissions of many diseases are via blood borne mode. Several activities are related to this transmission such as injection, blood transfusion and transplantation. Also, the acupuncture practice can be a possible route for blood borne infectious disease transmission. In this specific review, the author briefly reviews acupuncture and blood borne viral infections.
\end{abstract}

Keywords acupuncture, blood, virus, infection

\section{INTRODUCTION}

Blood borne infectious diseases are usually a public concern. The transmissions of many diseases are via blood borne mode. More than thirty pathogens are confirmed for the possibility of blood borne transmission. Those pathogens include bacteria, viruses as well as parasites. The blood borne transmission is one of the most common means for pathogen transmission. This can be seen in any setting around the world. The occurrence of a new infection at present is usually related to the blood borne transmission. Hence, the blood borne infectious diseases are still the diseases to be focused upon in disease surveillance at present.

By definition, a blood borne infectious disease means any disease that can be transmitted via the blood. Blood contact in any way in any appropriate amount in a proper environment can result in the transmission of pathogens. Several activities are related to transmission such as injection, blood transfusion and transplantation. Also, the acupuncture practice can be a possible route for blood borne infectious disease transmission. Indeed, acupuncture is a well-known and useful classical treatment, based on a theory of qi channels stimulating by needles, originating from China. The main mechanism of the infection is due to a minor trauma during acupuncture. For certain, if there is blood leakage, the contaminated blood borne pathogens can enter into the blood stream and further cause the problem. In this specific review, the author briefly reviews acupuncture and blood borne viral infections.

\section{HIV}

Human immunodeficiency virus (HIV) is a well known retrovirus in medicine. It is one of the most common viral infectious diseases at present. Since its first appearance nearly three decades ago, HIV infection has become a public health problem for all countries around the world. It is spread globally by infected patients and transmission via blood borne and sexual transmissions. Hence, the control of HIV infections at present usually focuses on the control of blood and sexual transmissions.

\footnotetext{
"Correspondence: Viroj Wiwanitkit

E-mail: wviroj@yahoo.com

Received March 5, 2012; Accepted May 14, 2012; Published May 31, 2012

doi: http://dx.doi.org/10.5667/tang.2012.0007

(C2012 by Association of Humanitas Medicine

TANG / www.e-tang.org
}

HIV transmission by acupuncture is of interest. This means of HIV transmission is not frequently mentioned. The first report on the acupuncture-related HIV infection was published in Vittecoq et al. (1989). After that there have been sporadic reports on acupuncture-related HIV infections and this issue has become a topic of concern with the safety of the traditional acupuncture practice (Cheng, 1989; Wiwanitkit, 2003). The concern is related to the knowledge and practice of the traditional acupuncture therapists. The safety and cleanliness of acupuncture is of great consideration. There is an interesting report on the knowledge, attitudes and behavior of acupuncture therapists (Hirose et al., 1995). It is noted that some practitioners lacked a good knowledge of HIV and its prevention and this might be problematic in daily acupuncture practice (Hirose et al., 1995).

Simply, the transmission can occur in the case that acupuncture therapists use a needle in HIV infected cases and repeatedly use it with the other patients without following proper procedures of cleanliness for used needles. It is shown that several HIV infection cases were through the use of acupuncture (Arbisi and Panpanich, 2008; Gore-Felton et al., 2003). The reasons are for social support, psychological well-being, clinical symptoms and analgesic avoidance (Arbisi and Panpanich, 2008). Nevertheless, the existence of HIV infection in HIV-infected cases has not proven to be statistically related to the previous history of acupuncture (Shi et al., 2006). The overwhelming of the risk of HIV infection due to acupuncture should not be acceptable (Levy, 2003).

Finally, although acupuncture has been proven to be a possible means of HIV transmission, it should be noted that there is also some evidence that acupuncture can be an alternative traditional method to improve the immune function among HIV infected patients (Wu, 1992).

\section{Hepatitis B}

Hepatitis B virus (HBV) is another virus in medicine. It is one of the prevalent viruses with millions of people worldwide acting as carriers. HBV infection is a public health problem for all countries around the world, especially those in tropical Asia. HBV infection can result in liver disease. Due to the carcinogenesis properties of $\mathrm{HBV}$, its more serious outcome is hepatocellulcar carcinoma. The mode of HBV transmission is the same as that of HIV and it can sometimes co-transmitted. Hence, the control of HIV infection at present usually focuses on the control of blood and sexual transmissions. 
HBV transmission by acupuncture is also of interest. Similar to the case of HIV, acupuncture-related HBV transmission is not frequently talked about. Indeed, due to the nature of the virus that can be more easily transmitted, the acupuncture-related HBV transmission should be easier than the case of acupuncture-related HIV transmission. In a report by Nalpas et al. (2000), it is shown that acupuncture has a higher risk for infection than blood transfusion. In another report from Mexico, acupuncture is one of the main underlying conditions for the case of HBV-present liver diseases (Alvarado-Esquivel et al., 2006). There are many interesting reports on the outbreak of HBV infection due to acupuncture. Examples of these reports include outbreaks in Jerusalem (Slater et al., 1988) and London (Walsh et al., 1999). It is recommended that $\mathrm{HBV}$ immunization be provided to all acupuncture therapists and the universal precaution is required for control of the acupuncture practice (Slater et al., 1988; Walsh et al., 1999).

Finally, in the endemic area of HBV, it is reported that acupuncture is one of independent predictors of $\mathrm{HBsAg}$ positivity (Lim, 2009; Nguyen et al., 2007). It is suggested that good acupuncture practices should be used to avoid iatrogenic acupuncture-related HBV transmission (Reynolds and McKee, 2008).

\section{Hepatitis C}

Hepatitis $\mathrm{C}$ virus (HCV) is another important hepatitis virus. Similar to HBV, HCV infection is a public health problem for all countries around the world with millions of silent carriers. Similar to the HBV infection, the HCV infection can result in liver disease and consequent liver cancer. The mode of HCV transmission is the same as those of HIV and HBV, hence, the control of HCV infection at present usually focuses on the control of blood and sexual transmissions.

Of interest, it is shown that only blood transfusion and acupuncture are the risk factors for HCV infection (He et al., 2011; Kim et al., 2011; Michitaka et al., 1991; Shin, 2006). There are also reports confirming acupuncture-related HCV transmission (Aikawa and Kojima, 2004; Chen et al., 1995; Sun et al., 1999). Chen et al. (1999) studied the problem of acupuncture-related HCV infection in Taiwan and concluded that "a more vigorous effort to prohibit the use of nondisposable needles should be promoted to interrupt the spread of community-acquired HCV infection"

\section{CONCLUSION}

There have been many confirmations that blood borne viral infections can be transmitted via acupuncture. The good control of sanitation in the acupuncture process is necessary. There should be strong protocols for universal precautions in medical centers providing acupuncture. The controls should also be expanded to the traditional acupuncture practice. All problems can be simply solved by the use of sterile disposable needles. Thus, legislation related to the use of disposable needles is the most important point.

\section{CONFLICT OF INTEREST}

The authors have no conflicting financial interests.

\section{REFERENCES}

Aikawa T, Kojima M. Transmission of hepatitis C virus (HCV) TANG / www.e-tang.org by tattooing and acupuncture. Nihon Rinsho. 2004;62:330-334.

Arbisi A, Panpanich R. Acupuncture use among people living with HIV/AIDS in Northern Thailand: motives, barriers, and attitudes. J Med Assoc Thai. 2008;91:533-541.

Alvarado-Esquivel C, Arellano-Santos CV, Salazar-Arana JL, Mercado-Suárez MF. Prevalence of hepatitis B virus infection in patients suffering from acute and chronic liver disease in three public hospitals in Durango, Mexico. Gac Med Mex. 2006;142:447-450.

Chen TZ, Wu JC, Yen FS, Sheng WY, Hwang SJ, Huo TI, Lee $\mathrm{SD}$. Injection with nondisposable needles as an important route for transmission of acute community-acquired hepatitis $\mathrm{C}$ virus infection in Taiwan. J Med Virol. 1995;46:247-251.

Cheng TO. Acupuncture and acquired immunodeficiency syndrome. Am J Med. 1989;87:489.

Gore-Felton C, Vosvick M, Power R, Koopman C, Ashton E, Bachmann MH, Israelski D, Spiegel D. Alternative therapies: a common practice among men and women living with HIV. J Assoc Nurses AIDS Care. 2003;14:17-27.

He Y, Zhang J, Zhong L, Chen X, Liu HM, Wan LK, Wang H, Li H, Tian L, Hu JL, Luo P, Wang L, Chen Y, Liu T, Liu SL, Lü WB. Prevalence of and risk factors for hepatitis $\mathrm{C}$ virus infection among blood donors in Chengdu, China. J Med Virol. 2011;83:616-621.

Hirose K, Tajima K, Fujihira N, Hasegawa S, Fujioka M. AIDS/HIV related knowledge, attitude and behavior of acupuncture therapists in Aichi Prefecture. Nihon Koshu Eisei Zasshi. 1995;42:269-279.

Kim JY, Won JE, Jeong SH, Park SJ, Hwang SG, Kang SK, Bae SH, Kim YS, Lee HC. Acute hepatitis C in Korea: different modes of infection, high rate of spontaneous recovery, and low rate of seroconversion. J Med Virol. 2011;83:1195-1202.

Levy DS. Statement about risks of acupuncture is misleading. Am Fam Physician. 2003;68:1713.

Lim YS. Current status of liver disease in Korea: hepatitis C. Korean J Hepatol. 2009;15 Suppl 6:S25-28.

Michitaka K, Horiike N, Ohta Y. An epidemiological study of hepatitis $\mathrm{C}$ virus infection in a local district in Japan. Rinsho Byori. 1991;39:586-591.

Nalpas B, Zylberberg H, Dubois F, Presles MA, Gillant JC, Lienard M, Delemotte B, Bréchot C. Prevalence of infection by hepatitis viruses in a rural area. Analysis according to risk factors and alcohol consumption. Gastroenterol Clin Biol. 2000;24:536-540.

Nguyen VT, McLaws ML, Dore GJ. Highly endemic hepatitis $\mathrm{B}$ infection in rural Vietnam. J Gastroenterol Hepatol. 2007;22:2093-2100.

Reynolds L, McKee M. Possible risks of transmission of bloodborne infection via acupuncture needles in Guizhou province, southwest China. J Altern Complement Med. 2008;14:1281-1285.

Shi XM, Yang ZM, Qian HZ, Qiao XC, Gao JH, Zheng XW, 2012 / Volume 2 / Issue 2 / e13 
Wang N. A cross-sectional survey on human immunodeficiency virus infection in a former commercial blood donating community, Shanxi Province. Zhonghua Yu Fang Yi Xue Za Zhi. 2006;40:427-432.

Shin HR. Epidemiology of hepatitis $\mathrm{C}$ virus in Korea. Intervirology. 2006;49:18-22.

Slater PE, Ben-Ishai P, Leventhal A, Zahger D, Bashary A, Moses A, Costin C, Shouval D. An acupuncture-associated outbreak of hepatitis B in Jerusalem. Eur J Epidemiol. 1988;4:322-325.

Sun CA, Chen HC, Lu CF, You SL, Mau YC, Ho MS, Lin SH, Chen CJ. Transmission of hepatitis $\mathrm{C}$ virus in Taiwan: prevalence and risk factors based on a nationwide survey. $\mathrm{J}$
Med Virol. 1999;59:290-296.

Vittecoq D, Mettetal JF, Rouzioux C, Bach JF, Bouchon JP, Acute HIV infection after acupuncture treatments. N Engl J Med. 1989;320:250-251.

Walsh B, Maguire H, Carrington D. Outbreak of hepatitis B in an acupuncture clinic. Commun Dis Public Health. 1999;2:137-140.

Wiwanitkit V. HIV infection after Chinese traditional acupuncture treatment. Complement Ther Med. 2003;11:272

Wu B. Recent development of studies on traditional Chinese medicine in prophylaxis and treatment of AIDS. J Tradit Chin Med. 1992;12:10-20. 